\title{
CONCEPÇÕES DE ALUNOS DO ENSINO MÉDIO SOBRE A ORIGEM DAS ESPÉCIES
}

\author{
High School students' conceptions \\ about the origin of species
}

David Figueiredo de Almeida ${ }^{1}$

Resumo: Este trabalho teve por objetivo analisar as concepções de estudantes de Ensino Médio, em Macapá (Amapá, Brasil), a respeito da origem das espécies. Por meio de questionários, observou-se a predominância da concepção criacionista descrita na Bíblia, em sua interpretação literal. A concepção evolucionista tendeu a ser mais frequente somente quando aplicada às espécies não humanas. Registraram-se, ainda, contradições entre algumas ideias dos alunos e a teoria da evolução, que também demonstrou ser pouco compreendida pelos pesquisados. Estas observações indicam a necessidade de intervenções educativas para minimizar a problemática observada, contribuindo para o maior diálogo entre as concepções dos alunos e o ensino de evolução.

Palavras-chave: Evolução. Ensino de evolução. Ensino de ciências.

\begin{abstract}
The objective of this work was to analyze high school students' conceptions about the origin of species, in Macapá (Amapá, Brazil). Through questionnaires, the predominance of the creationist conceptions as described in the Bible, in its literal interpretation, were observed. The evolutionist conception tended to be more frequent when applied to non-human species. There were some contradictions between the students' ideas and the theory of evolution, which also appeared to be poorly understood by students. These observations indicate the need for educational interventions to minimize the reported problems, contributing to a dialogue between the students' conceptions and the teaching of evolutionary theory.
\end{abstract}

Keywords: Evolution. Evolution Theory. Science teaching.

\footnotetext{
${ }^{1}$ Instituto Federal de Educação, Ciência e Tecnologia do Amapá (IFAP). Rodovia BR 210, Km 3, s/n, Brasil Novo. Macapá, AP, Brasil. 68.908-198. david.almeida@ifap.edu.br
} 
Almeida, D. F.

\section{Introdução}

"O ser humano sempre demonstrou uma preocupação constante com as origens e com as causas. Essa preocupação se manifesta desde a infância, na 'idade dos porquês': tudo deve ter uma causa" (BRANCO, 2004, p. 19). Do mesmo modo, a busca pelo entendimento e explicação do mundo vem se manifestando desde tempos remotos (FONSECA, 2004), quando diferentes povos, em diferentes partes do mundo, deram versões próprias às suas indagações sobre as origens, o que ajuda a explicar a existência de milhares de mitos que povoam o imaginário destas comunidades. Paralelamente, cientistas também lançaram hipóteses à questão, esforçando-se para prová-las (RAGACHE, 2005). No campo da mitologia, os relatos a respeito da origem das espécies são geralmente protagonizados por uma ou várias entidades divinas ou espíritos. Em geral, um deus supremo (demiurgo) se contenta em criar os homens e alguns animais. Em seguida, outros deuses ou espíritos complementam a obra, criando as plantas e os demais elementos naturais (RAGACHE, 2005).

Existe uma vasta literatura antropológica sobre diferentes concepções de origem das espécies, como concepções de nativos africanos, americanos, nórdicos, australianos etc. Para este trabalho, alguns exemplos foram obtidos de fontes como Ragache (2005), Prado (2005) e Freund (2008).

Segundo algumas narrativas do candomblé, por exemplo, o ato da criação foi protagonizado por mais de uma entidade. Conforme Prado (2005), para o candomblé praticado por descendentes da etnia iorubá, a criação do mundo e dos seres foi marcada pelas disputas entre dois orixás, Obatalá e Oduduá, mediados por um deus maior, Olodumaré. Este atribuiu a Obatalá a importante tarefa de criar o mundo, dando-lhe para isso um saco com areia, uma galinha e um camaleão. Rumo à sua missão, Obatalá se embriagou no caminho e Oduduá lhe roubou o saco da criação, com o qual criou o mundo. Indignado, Obatalá reclamou a Olodumaré, que the deu mais uma chance: criar os homens. Assim, este povo conta que Oduduá criou o mundo e Obatalá criou a espécie humana.

Ragache (2005) relata que, na mitologia maia, sete deuses (Tepen Operário, Gucumatz Nobre, Huracan e os Quatro Guardiães) se reuniram em conselho e decidiram pela criação do mundo. Huracan lançou trovões e raios, que fizeram surgir o solo, o mar, as plantas etc. Os deuses, felizes com este resultado, decidiram criar seres que pudessem parabenizá-los e enaltecê-los pela obra. Criaram, então, as primeiras espécies de animais, como aves, serpentes e outras feras. Porém, estes animais só eram capazes de gorjear ou rugir e, por esta razão, foram condenados a ser perseguidos e devorados. Os deuses, porém, não desistiram: modelaram, primeiramente, os homens a partir de terra úmida, depois, de madeira e, finalmente, de milho, esta última a única matéria-prima que realmente apresentou resultados satisfatórios.

Outro relato bastante interessante vem dos índios Waiäpi, do Amapá. Gallois (2007) relata que, para este povo, os primeiros seres humanos (os próprios Waiäpı) surgiram sob os cuidados do criador, Janejar. Os demais povos indígenas surgiram como produto da putrefação de larvas provindas de ovos depositados por abelhas em cadáveres de grandes serpentes, povos estes tão hostis (ou não) quanto as abelhas que iniciaram o processo. Os demais povos (brancos, negros etc.) teriam caído do céu na forma de pedras de diferentes cores, originando as diferentes "raças", ou, então, surgiram da chuva, e são tão numerosos quanto as gotas d'água. 
Um dos relatos mitológicos mais difundidos no mundo é, seguramente, o contido na Bíblia. A leitura prévia da Bíblia revela que "no princípio criou Deus o céu e a terra" (GÊNESIS, 2006, p. 17). No terceiro dia, após ter criado a luz, as águas, o deus cristão ordena que "produza a terra erva verde, que faça semente, e produza árvores frutíferas" (p. 17). A criação das primeiras plantas foi sucedida pela criação dos primeiros animais, como aves, grandes peixes, animais domésticos, répteis, "segundo as suas espécies" (p. 17). A origem do homem foi o ponto alto da criação divina. Foi criado, macho e fêmea, à "imagem e semelhança" de deus (p. 17). O primeiro homem foi chamado de Adão, e a primeira mulher, de Eva (STORNIOLO; BALANCIN, 2003).

Existem muitas maneiras de se interpretar todos estes mitos. Para Freund (2008), os mitos podem ser interpretados como "Arte e filosofia", como "Ciência primitiva" ou como "História literal". No primeiro caso, o autor descreve os mitos como obras de arte, como ficção, pois não é improvável que detalhes tenham sido exageradamente adicionados a muitos destes mitos, por cronistas ou poetas tribais, com o objetivo de impressionar ouvintes, há milhares de anos, ou ainda, pregar moral e transmitir instruções, por filósofos ou professores de tempos remotos. No segundo caso, o mito é visto por alguns naturalistas como tentativas primitivas de se solucionarem problemas, aos quais são propostas hipóteses que, ao contrário das hipóteses científicas, geralmente não são testáveis. Questionando-se sobre a origem de trovões, por exemplo, o homem primitivo talvez tenha formulado muitas hipóteses, como a de que os trovões nada mais são do que a voz de um deus maior furioso, que lança raios para punir os homens. No terceiro caso, é possível que algumas partes dos mitos sejam, na verdade, testemunhos de acontecimentos de muito tempo atrás. Um exemplo pode ser o relato Waiäpi para a origem dos homens, apresentado anteriormente: seriam as pedras que supostamente caíram do céu, na verdade, meteoritos ou algo parecido? E a putrefação de vermes em cadáveres de grandes serpentes? Embora pareça irreal o surgimento espontâneo de homens a partir de larvas de abelhas, certamente este relato surgiu da observação de um processo cientificamente válido (a relação entre a putrefação e a deposição de ovos de insetos em cadáveres).

Brown (1995) e Storniolo e Balancin (2003) trazem uma interpretação histórica dos relatos do Gênesis. Conforme os autores, os primeiros relatos do Gênesis são de autoria de Sacerdotes (586-538 a.C.), que teriam registrado mitos populares no Oriente Médio há milhares de anos, num período em que os judeus corriam o risco de perder sua identidade, religião e cultura, durante o exílio na Babilônia. Para evitar que seu povo sofresse influência dos cultos babilônicos, sacerdotes reuniram, num único material, contos de tradição oral mesclados a mitos, histórias folclóricas, alegorias, parábolas e verdades religiosas sobre deus e o homem, na tentativa de salvar a cultura de seu povo.

Frente a tantos significados que os mitos podem apresentar (fragmentos de observações reais, imaginação, valor moral, hipóteses não científicas etc.), parece não fazer sentido atribuir-lhes um estatuto científico (BROWN, 1995), rivalizando-os com a ciência, mas sim considerar que diferentes sistemas de conhecimento podem ser complementares, não inimigos (MOCHÓN, 2005).

Cientistas, assim como povos do mundo todo, também foram em busca de respostas para a questão das origens. As primeiras ideias pré-evolucionistas para a origem das espécies surgiram possivelmente entre filósofos como Anaximandro (séc. VI a.C.), Xenófanes (séc. V a.C.), Aristóteles (séc. IV a.C.) e outros (MOODY, 1975). Mas, foi no século XVIII que o 
Almeida, D. F.

naturalista francês Jean-Baptiste Lamarck alertou a comunidade científica para a adaptação das espécies às condições do meio, mas se equivocou ao afirmar que estas poderiam sofrer mudanças hereditárias por esforço próprio, em resposta às condições ambientais (BRANCO, 2004). Em 1859, o naturalista inglês Charles Darwin publicou a obra "A Origem das Espécies", a qual "causou uma verdadeira revolução na biologia e no próprio pensamento humano" (BRANCO, 2004, p. 41), sendo imediatamente aceita pela comunidade científica, ainda que acusada de imoral pelos religiosos criacionistas, por considerar que os mecanismos evolutivos também se aplicariam à espécie humana, que teria surgido a partir de primatas pré-históricos, como ilustra Soares (1990). Descobertas realizadas ao longo do século XX possibilitaram a validação e reinterpretação da maior parte das ideias de Darwin, especialmente a seleção natural, configurando a evolução cada vez mais como um conjunto de princípios explanatórios sofisticados, intrincados e abrangentes (FUTUYMA, 2009).

Mesmo que, nos limites da ciência, poucos duvidassem que diferentes seres pudessem ter uma origem comum (MOCHÓN, 2005), isso não foi suficiente para evitar que se formasse, ao longo do século XX, uma cruzada criacionista contra Darwin e a evolução, especialmente nos Estados Unidos, onde o ensino da evolução chegou a ser banido em quatro estados: Oklahoma, Tennessee, Mississipi e Arkansas (TAMBOSI, 1999). Tendo ocorrido na potência hegemônica do planeta, o fenômeno das disputas entre criacionistas e evolucionistas no âmbito escolar viria a ter um efeito de irradiação poderoso (MARTINS, 2001). No Brasil, o governo do Rio de Janeiro implantou, nas suas escolas, em 2002, o ensino religioso confessional para, num segundo momento, incorporar, em seu conteúdo programático, o criacionismo como explicação para a origem das espécies, a partir da leitura literal das escrituras bíblicas, textos importantíssimos como documentos históricos, cuja linguagem alegórica é reconhecida por várias lideranças religiosas (MARTINS, 2004).

Embora os conceitos evolutivos sejam considerados fundamentais para questões envolvendo a sociedade moderna, como, por exemplo, a descoberta de vacinas e intervenções que possam conter a disseminação da AIDS (MEYER; EL-HANI, 2005), importância amplamente reconhecida por documentos como os Parâmetros e Diretrizes Curriculares Nacionais (BRASIL, 2006), pesquisas desenvolvidas no campo da Educação revelam que os estudantes entendem pouco a evolução, "apontando a pertinência de estudos adicionais na área” (SANTOS, 2002, p. 9). Para a autora, investigar as concepções dos estudantes é relevante para "a elaboração de estratégias de ensino mais eficazes" (p. 7), visto que, na maioria das vezes, o aluno traz conhecimentos prévios à sala de aula, os quais representam seus contextos socioculturais, suas realidades, suas histórias de vida (FONSECA, 2004), incluindo-se aí as concepções não científicas, que podem ou não entrar em conflito com a concepção evolucionista, dependendo, dentre outros fatores, das concepções dos alunos e das abordagens dos professores.

Assim, os objetivos deste trabalho foram: investigar as concepções de alunos de uma escola de Ensino Médio a respeito da origem das espécies; identificar ideias que possam obstaculizar um maior diálogo entre a concepção evolucionista e as demais concepções; avaliar os conhecimentos dos alunos acerca da teoria da evolução; a partir destas observações, contribuir com propostas para o ensino de biologia numa relação dialógica entre conhecimento científico e os demais sistemas de conhecimento. 


\section{Procedimentos metodológicos}

A metodologia adotada foi a da pesquisa social, conforme Minayo (2002) e Gil (1999), pautada num estudo descritivo com abordagem qualitativa, onde algumas variáveis estudadas foram, no entanto, quantificadas de forma a complementar os dados qualitativos.

Participaram deste estudo alunos de Ensino Médio da Escola Estadual Raimunda Virgolino, localizada na zona urbana de Macapá (Amapá, Brasil). Alunos de todas as 27 turmas de Ensino Médio desta escola foram convidados a participar como voluntários do trabalho. No total, 156 voluntários foram conduzidos ao auditório da escola, onde foram esclarecidos acerca dos objetivos da pesquisa e receberam instruções sobre os procedimentos a serem seguidos ao longo da coleta de dados.

O primeiro instrumento usado consistiu num questionário com perguntas abertas onde os alunos puderam discorrer sobre suas concepções da origem da espécie humana e das demais espécies de seres vivos. Optou-se por perguntas abertas porque, sendo "uma pesquisa inicial, exploratória, não conhecendo a abrangência ou a variabilidade das possíveis respostas, são necessárias perguntas abertas" (GUNTHER, 2003, p. 16). As respostas mais frequentes ou de maior destaque foram transcritas literalmente, omitindo-se a identificação do aluno. Ademais, verificou-se a tendência de os discursos discentes se enquadrarem como concepções evolucionistas, criacionistas ou outras que pudessem ser registradas.

O segundo instrumento foi um questionário fechado, com questões envolvendo conceitos básicos de evolução, com cinco opções de resposta. Neste caso, como a intenção era verificar se os alunos responderiam conforme o proposto pela evolução, optou-se por um questionário fechado.

\section{Resultados e análise}

A análise dos questionários demonstrou que $89 \%$ dos alunos se identificaram como católicos $(66 \%)$ ou evangélicos (23\%); 10\% afirmaram não possuir nenhuma religião, e 1\% se declararam ateus. Em sua maioria, os alunos pertencem ao gênero feminino $(58 \%)$, com idade entre 14 e 28 anos.

A concepção criacionista foi a mais frequente quando aos alunos se perguntou acerca da origem do homem, tendo atingido mais do que o dobro da porcentagem da concepção evolucionista (Figura 1). Ainda na Figura 1, percebe-se que a frequência da concepção evolucionista se elevou consideravelmente quando os estudantes se manifestaram sobre a origem das demais espécies, que não a humana. Tanto a concepção criacionista para a origem do homem quanto para a origem das demais espécies corresponde, em linhas gerais, às descrições do Gênesis, da Bíblia. Não foram registradas outras explicações criacionistas além desta.

Observa-se que há razoável tendência de se adotar a concepção criacionista no que se refere à espécie humana. No entanto, muitos estudantes abrem mão da explicação criacionista quanto às demais espécies. Em outras palavras, aceitam a teoria evolutiva, desde que não seja aplicada ao ser humano, visão esta também bastante comum no mundo islâmico (CHANG, 2009). 
Almeida, D. F.

Figura 1. Distribuição dos alunos quando questionados sobre a origem da espécie humana e das demais espécies.

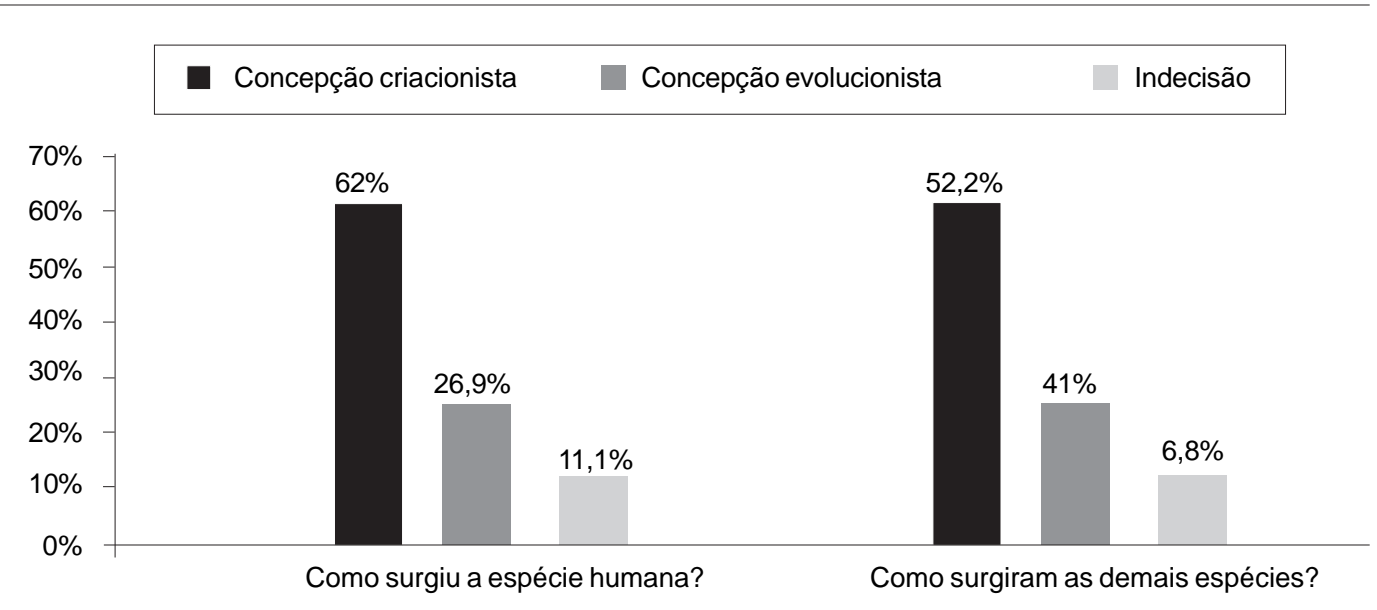

Fonte: O autor.

No discurso dos estudantes foram registradas várias contradições, tanto na concepção criacionista quanto na evolucionista, como a transcrita a seguir: "Muitos cientistas falam que o homem surgiu do macaco". Homens e macacos (como chimpanzés) são, na versão científica, parentes próximos na natureza, e o ancestral que os originou era um animal semelhante aos macacos que conhecemos hoje (MEYER; EL-HANI, 2005). Segundo Carneiro (2004), é mais simples explicar que o homem se originou de macacos a explicar que ambos têm um ancestral comum, o que exigiria o conhecimento deste. Alguns autores, como Santos (2002) e Almeida (2010), consideram que a sociedade ocidental contém, exageradamente, sentimentos de egocentrismo e antropocentrismo, julgando-se superior a todas as demais espécies vivas. Assim, o fato de as escrituras bíblicas relatarem, à primeira vista, que a espécie humana fora criada à imagem e semelhança de deus talvez seja uma das barreiras para aceitação da evolução humana (SANTOS, 2002), ou seja, as pessoas prefeririam se assemelhar a uma entidade divina a ter parentesco com primatas pré-históricos, o que poderia explicar as diferenças nos resultados da Figura 1.

Em outro registro, verificou-se que a falta de compreensão da evolução como processo lento pode ser mais uma barreira à sua aceitação: "Um primata não pode evoluir. Se pudesse, até hoje veríamos os primatas evoluindo". O conceito de evolução, como o de átomos, genes, gravitação etc., é aceito por ser apoiado por evidências advindas de testes empíricos, mesmo não sendo diretamente visto, sentido ou escutado com qualquer dos órgãos sensoriais (MEYER; ELHANI, 2005). Além disso, conceitos como os de recombinações gênicas, mutações e seleção natural podem ser facilmente contextualizados ao dia-a-dia dos alunos, tornados parte do processo evolutivo mais familiar e observável.

Embora a origem do universo e do homem sejam acontecimentos diferentes, foi comum a concepção discente de que o surgimento do homem e dos demais seres foi causado pelo big bang, teoria que explica, na verdade, apenas a origem do universo: "Na minha opinião, 
o homem não surgiu daquela explosão que é conhecida como big bang e sim tudo foi criado por Deus". A mesma crença foi verificada em alunos que afirmaram adotar a concepção evolucionista: "Acredito que o surgimento do homem ocorreu através de uma explosão". Ainda confundindo evolução com big bang, um terceiro aluno usa o seguinte argumento: "A espécie bumana surgiu a partir da criação. Não acredito que venha ter sido com o surgimento de uma explosão, porque uma explosão só faz destruir e não transformar". Neste último caso, observação semelhante foi feita por Fonseca (2004).

Uma das mais poderosas razões do descrédito na teoria da evolução consiste na falta de discussão acerca do significado que o termo "acaso" tem na ciência, o que leva os alunos a considerarem o caráter supostamente "aleatório" de mecanismos evolutivos, como seleção natural e mutação (SEPÚLVEDA; EL-HANI, 2004), dificultando ainda mais a compreensão da teoria evolutiva. Segundo Branco (2004), existe uma dificuldade natural do ser humano em aceitar a ocorrência de fenômenos e ações que não possuam uma finalidade explícita. Tudo o que o homem faz deve ter uma finalidade. A esta ideia, Lacadena (2008) chama de Teleologia Externa ou Finalismo. Para este autor, pensar a evolução em geral e a origem do homem como fenômenos aleatórios, ao acaso, é aceitar que o homem está sozinho na imensidão do universo, onde surgiu por pura sorte.

A solução encontrada por alguns alunos para conciliar o "acaso" da evolução foi incluir a participação divina neste processo: "Não sei o que falar. Não acho que surgimos por acaso. Deve ter o 'dedo' de alguém. É o que eu acho". Outra aluna mesclou evolução com sua concepção criacionista: "Acredito que a espécie bumana foi, sim, criada pelo Senhor Deus. Contudo, com o passar do tempo, o homem passou a evoluir tanto no aspecto social quanto no fisico". Argumento semelhante foi defendido por este aluno: "Deus criou o mundo e deu algum jeito para que as coisas se combinassem e evoluissem por si só, sem a ajuda dele".

Todas essas ideias se aproximam do que é defendido pelo movimento chamado evolucionismo teísta, onde todo o processo evolutivo é intermediado pela vontade divina, conforme definição de Scott (2001). É possível que um incômodo em terem de escolher entre o conhecimento científico e o religioso leve esses alunos a sintetizarem criação e evolução, compatibilizando suas visões de mundo à teoria evolutiva (FONSECA, 2004). Para Reiss (2008), ciência e religião podem ser vistas como passíveis de integração, uma vez que existem modelos onde ambas são sócias, contribuindo para uma visão multilateral do mundo.

Porém, julga-se que, para que o aluno integre suas concepções particulares à concepção evolucionista e vice-versa, é importante pôr em discussão estas e outras ideias que possam dificultar ou impedir esta integração.

Em diversos casos, por exemplo, notou-se certa tendência dos alunos a considerarem obrigatória a relação entre evolução e ateísmo. Tal correlação pode ser observada no discurso de um aluno declarado ateu: "Deus não crion o mundo e nem os seres vivos. Nós somos frutos da evolução das espécies, de organismos mais primitivos, até porque Deus foi criado na idade média. Deus não criou nada, a não ser histórias mirabolantes. P. S: Não sou anticristo!". No outro extremo, parece obrigatória a relação entre a fé na existência divina e a aceitação dos relatos criacionistas, com a consequente rejeição da concepção evolucionista: "Acredito em Deus, e consequentemente acredito que o mundo foi criado por ele". Em outro discurso, é nítida a aceitação de um caráter inquestionável das escrituras bíblicas, o que talvez não abra qualquer possibilidade para um diálogo com a concepção evolucionista: "Tudo que existe na Terra foi Deus que criou, pois se tudo isso fosse mentira não estaria escrito na palavra de Deus". Autores como Schoroeder (1990), Brown (1995), Storniolo e 
Balancin (2003), Branco (2004) e Meyer e El-Hani (2005), ratificam que a incompatibilidade entre criação e evolução surge, de fato, desta interpretação literal do livro do Gênesis. É um equívoco pensar que todo cientista é ateu ou que todo religioso rejeita a ciência (SMITH; SIEGEL; McINERNEY, 1995).

O fato de a explicação criacionista ser a primeira adotada, por muitos alunos, para a origem das espécies, pode ser exemplificado com esta citação: "Desde criança, meus avós e mens pais me ensinaram e me mostraram que tudo que existe foi criado por Deus". De maneira geral, as religiões têm uma dimensão prática e ritual que abrange elementos como adoração, pregação, meditação, oração e outras formas de buscar a paz interna. Quando os alunos ingressam no Ensino Médio, esta dimensão pode sofrer conflito ou ser interrompida por explicações científicas que são tão diferentes de suas crenças pessoais (REISS, 2008).

"O único problema é que os cientistas querem ser mais importantes que o criador do universo, $e$ querem provar algo que não tem fundamento [a evolução das espécies]". Neste discurso, os cientistas são vistos como profissionais arrogantes que tentam superar a imagem divina. É provável que tal crença se origine a partir da equivocada ideia segundo a qual a ciência é infalível, o que a aproximaria, em termos conceituais, de uma entidade divina onipotente. Porém, se por um lado todo conhecimento científico está sujeito a modificações, por outro, o conhecimento religioso, não partindo de hipóteses testáveis, se baseia em premissas consideradas verdades absolutas, isto é, fundamentadas na fé (SMITH; SIEGEL; McINERNEY, 1995). Isto significa dizer que questões como a existência de deuses não são passíveis de verificação e, portanto, fogem do alcance da pesquisa científica, razão pela qual ela não está respaldada para fazer qualquer julgamento a este respeito. Não se pode formular e experimentar hipóteses para a existência de quaisquer entidades divinas, simplesmente porque cientistas só fazem experimentos com montanhas, astros, ecossistemas naturais, pessoas e a própria evolução das espécies (MOCHÓN, 2005).

Os dados referentes ao segundo instrumento de pesquisa apontam para o pouco conhecimento que os alunos possuem sobre a teoria evolutiva. Este pouco conhecimento foi evidenciado tanto nos alunos de concepção criacionista quanto nos de concepção evolucionista. Em média, cada aluno tendeu a acertar menos de duas das oito questões objetivas propostas neste instrumento $(23,2 \%$ de acerto).

Em linhas gerais, constatou-se que: 71\% ignoraram Charles Darwin como o maior evolucionista de todos os tempos, assinalando outros nomes como Galileu Galilei, Robert Hooke, Gregor Mendel e Carlos Lineu; 86\% não assinalaram que "A Origem das Espécies" é o maior clássico já publicado sobre evolução; apenas $28 \%$ e $38 \%$ assinalaram os conceitos de "mutação" e "seleção natural" como diretamente ligados à evolução, respectivamente; $90 \%$ concordaram que as metamorfoses sofridas por lagartas e girinos são exemplos de espécies evoluindo para outras espécies; $83 \%$ assinalaram que a ciência prega a descendência do homem a partir de primatas como chimpanzés, gorilas e orangotangos; $75,5 \%$ acreditam que os morcegos sejam mais aparentados às aves do que ao homem, desconhecendo que ambos têm mais homologias entre si do que com as aves, já que se sabe que a evolução se reflete na classificação dos organismos (MOODY, 1975); apenas 31,5\% dos alunos reconhecem que, segundo a biologia, a vida na Terra surgiu por volta de 3,5 bilhões de anos, assinalando, inclusive, que tal fato se deu há 150 bilhões de anos (21\%), período de tempo pouco realista, mesmo se considerássemos a idade do universo. 
Futuyma (2009) acredita que nenhuma pessoa destituída de conhecimentos pode negar a realidade da evolução das espécies. No entanto, este pressuposto perde um pouco de sentido a partir da observação de que, das três maiores pontuações (acerto em mais de 75\% das questões) verificadas no segundo instrumento de pesquisa, duas vieram de alunos que anteriormente explicaram a origem do homem e das demais espécies segundo a concepção criacionista. Santos (2002) lança a possibilidade de que os alunos podem aprender os conceitos evolutivos, mas não necessariamente têm de apreendê-los, ou seja, substituir suas visões de mundo. Ainda assim, é relevante que, ao menos certas ideias preconcebidas sejam trabalhadas, pois não correspondem ao proposto pela evolução, já que as concepções prévias dos alunos são determinantes no "como" eles aprendem e no "se aprendem" (ALTERS; NELSON, 2002).

Um conceito que pode explicar o fato de alguns alunos terem muitos conhecimentos sobre a evolução, mas adotarem a concepção criacionista para a origem dos seres, é o do "apartheid cognitivo" (COBERN; LOVING, 2001; SEPÚLVEDA; EL-HANI, 2004; ALMEIDA, 2010), no qual os alunos podem isolar determinados conhecimentos científicos em "compartimentos" mentais, resgatando estes conhecimentos em situações tidas como importantes, como uma prova escolar. Outras hipóteses a serem consideradas são as de que alguns alunos criacionistas se informem mais acerca da evolução com o objetivo de refutá-la, ou ainda, que o ensino de evolução se torne mais significativo para estes alunos porque sua visão de mundo se choca com as informações veiculadas em sala de aula, enquanto parte dos alunos que não demonstram resistência à teoria é, ao mesmo tempo, mais indiferente em relação a ela.

Ratifica-se que, no presente trabalho, há indicativos do precário conhecimento sobre a teoria evolutiva em alunos de ambas as concepções (criacionista e evolucionista). Isto pode ser o reflexo de um possível descaso do ensino da evolução na escola visitada, o que é previsto, num contexto mais amplo, por vários autores, como Piolli e Dias (2004). Tanto o ensino quanto a aprendizagem deste tema são considerados problemáticos (SILVA, 2004).

Conforme Santos (2002, p. 20), os obstáculos epistemológicos são “idéias que podem impedir a compreensão de certos fenômenos" e que, caso estejam presentes na mente dos alunos, "poderiam oferecer resistência à acomodação de novas explicações". Existe, um complexo sinergismo que pode afetar a aprendizagem da evolução, no Ensino Médio: concepções prévias dos alunos em relação à evolução, orientação religiosa, a própria orientação científica etc. (ALTERS; NELSON, 2002). As situações aqui analisadas podem ser exemplos de obstáculos epistemológicos para o ensino de evolução.

\section{Considerações finais}

Este artigo demonstrou que a maioria dos alunos amostrados, da escola visitada em Macapá, concebeu a origem das espécies a partir da concepção criacionista apresentada pela Bíblia, não sendo registradas outras concepções criacionistas. A concepção evolucionista, por sua vez, tendeu a ser mais apresentada para a origem das espécies não humanas. Além disso, houve baixos níveis de acerto na avaliação de conhecimentos básicos sobre evolução, tanto em alunos criacionistas quanto em alunos evolucionistas.

Se por um lado o Amapá é considerado o estado mais preservado do Brasil, com grande diversidade de espécies, por outro, existe aí uma enorme diversidade cultural, onde 
vários povos indígenas e quilombolas, por exemplo, podem ter chegado a respostas alternativas para a origem das espécies, paralelamente à teoria da evolução e ao criacionismo bíblico estes últimos talvez os únicos modelos explicativos levados a sério pela maior parte da sociedade predominante. Em outras palavras, o importante acervo cultural amazônico, como patrimônio local, também deve ser levado em consideração.

Assim, propõe-se a inclusão de alguns destes sistemas explicativos locais em abordagens preliminares de evolução no contexto do ensino de biologia. O documento "Orientações curriculares para o Ensino Médio" traz a seguinte sugestão para o item "Origem e evolução dos seres vivos":

Os alunos seriam estimulados a pesquisar textos diversos sobre a origem da vida com explicações científicas atuais; explicações científicas do século 19; lendas indígenas, lendas da cultura oriental, textos extraídos da mitologia grega ou da Bíblia. Após a seleção dos textos, seria organizado um fórum de discussão para estabelecer distinção entre as concepções científicas e não-científicas e um debate em que parte dos alunos, baseados em argumentos construídos cientificamente, defenderia o acaso no surgimento da vida, e a outra parte defenderia a existência de um projeto orientando o seu aparecimento. (BRASIL, 2006, p. 29)

Deve-se considerar a possibilidade da presença contextualizada de outros sistemas explicativos, em abordagens introdutórias da evolução, não como relatos puramente científicos, como defendem os ativistas norte-americanos, mas como representações de diferentes povos sobre suas origens, extrapolando, até mesmo, os limites do ensino de biologia, de forma a interagir com outras áreas do conhecimento, como história, antropologia, filosofia, sociologia, psicologia, artes, princípio do que se conhece por interdisciplinaridade. É necessário que a organização e o tratamento dos conteúdos expressem a diversidade, rompam com o monoculturalismo e valorizem a pluralidade que existe na sociedade brasileira (BRASIL, 2006), contribuindo, assim, para a compreensão das diferenças metodológicas entre ciência e as demais esferas do conhecimento, e das possibilidades de um diálogo entre elas, no ensino de evolução.

\section{Agradecimentos}

O autor agradece aos alunos da Escola Estadual Raimunda Virgolino, que acolheram o trabalho e se dispuseram a participar como voluntários. À Profa. Dra. Dominique Tilkin Gallois (USP/SP), à Profa. Me. Cristiane Rodrigues Menezes (UNIFAP/AP) e ao Téc. Márcio Oliveira dos Santos (IFAP/AP), pela colaboração. Aos pareceristas anônimos da Revista Ciência \& Educação, pelas sugestões. 
Concepções de alunos do Ensino Médio ...

\section{Referências}

ALMEIDA, D. F. Pedras coloridas no ensino de evolução. Salto: Schoba, 2010.

ALTERS, B. J.; NELSON, E. Perspective: teaching evolution in higher education.

Evolution, Lawrence, v. 56, n. 10, p. 1891-1901, 2002.

BRANCO, S. L. Evolução das espécies: o pensamento científico, religioso e filosófico.

2. ed. São Paulo: Moderna, 2004.

BRASIL. Ministério da Educação e do Desporto. Secretaria de Educação Básica.

Orientações curriculares para o ensino médio: ciências da natureza, matemática e suas tecnologias. Brasília: Secretaria de Educação Básica, 2006. v. 2.

BROWN, S. L. Gênesis: uma interpretação esotérica. São Paulo: Pensamentos, 1995.

CARNEIRO, A. P. N. A evolução biológica aos olhos de professores não-licenciados. 2004. 119 f. Dissertação (Mestrado em Educação) - Centro de Ciências da Educação, Universidade Federal de Santa Catarina, Florianópolis, 2004.

CHANG, K. Criacionismo prospera no mundo islâmico, mas sem crença de Terra recente. Folha de S. Paulo, São Paulo, 12 nov. 2009. Disponível em: <http://

www1.folha.uol.com.br/folha/ciencia/ult306u651325.shtml>. Acesso em: 25 nov. 2009.

COBERN, W. W.; LOVING, C. C. Defining science in a multicultural world: implications for science education. Science Education, Salem, v. 85, n. 1, p. 50-67, 2001.

FONSECA, L. C. S. Religião popular: o que a escola tem a ver com isso? - pistas para repensar o ensino de ciências. 2004. 246f. Trabalho acadêmico (Requisito parcial para aprovação em disciplina do programa de pós-graduação em Educação) - Universidade Federal do Rio de Janeiro, Rio de Janeiro, 2004. Disponível em: <http:// www.bdtd.ndc.uff.br/tde_busca/arquivo.php?codArquivo=348>. Acesso em: 13 jan. 2009.

FREUND, P. Mitos da criação. São Paulo: Cultrix, 2008.

FUTUYMA, D. J. Biologia evolutiva. 3. ed. Ribeirão Preto: FUNPEC, 2009.

GALLOIS, D. T. Gêneses waiãpi, entre diversos e diferentes. Revista de Antropologia, São Paulo, v. 50, n. 1, p. 45-83, 2007.

GÊNESIS. Português. In: Bíblia sagrada. Tradução de Padre Antônio Pereira de Figueiredo. Rio de Janeiro: DCL, 2006, p. 16-62.

GIL, A. C. Métodos e técnicas da pesquisa social. 5. ed. São Paulo: Atlas, 1999.

GUNTHER, H. Como elaborar um questionário. Brasília: UnB, 2003.

LACADENA, J. R. Creación y evolución, creacionismo y evolucionismo. Selecciones de Bioetica, Bogotá, n. 14, p. 53-66, 2008.

MARTINS, M. V. De Darwin, de caixas-pretas e do surpreendente retorno do 'criacionismo'. História, Ciências, Saúde - Manguinhos, Rio de Janeiro, v. 8, n. 3, p. 739-756, 2001.

O criacionismo chega às escolas do Rio de Janeiro: uma abordagem sociológica.

ComCiência, n. 56, jul. 2004. Disponível em: < http://www.comciencia.br/200407/

reportagens/creditos.shtml>. Acesso em: 10 jan. 2010. 
Almeida, D. F.

MEYER, D.; EL-HANI, C. N. Evolução: o sentido da biologia. São Paulo: Ed. da Unesp, 2005.

MINAYO, M. C. S. (Org.). Pesquisa social: teoria, método e criatividade. 20. ed.

Petrópolis: Vozes, 2002.

MOCHÓN, J. A. A. La ciência frente a las creencias religiosas: ciencia y religión en los albores del nuevo milenio. Mientras Tanto, Barcelona, v. 95, p. 1-31, 2005.

MOODY, P. A. Introdução à evolução. Brasília: Editora UnB, 1975.

PIOLLI, A.; DIAS, S. Escolas não dão destaque à evolução biológica. ComCiência, n. 56, jul. 2004. Disponível em: <http://www.comciencia.br/200407/reportagens/creditos.shtml >. Acesso em: 10 jan. 2010.

PRADO, Z. A. Mitos da criação. São Paulo: Callis, 2005.

RAGACHE, C. A criação do mundo: mitos e lendas. 7. ed. São Paulo: Ática, 2005.

REISS, M. J. Teaching evolution in a creationist environment: an approach based on worldviews, not misconceptions. School Science Review, Hertfordshire, v. 90, n. 331, p. 46-56, 2008.

SANTOS, S. Evolução biológica: ensino e aprendizagem no cotidiano de sala de aula. São Paulo: Annablume, 2002.

SCHOROEDER, G. L. O gênesis e o big bang. 10. ed. São Paulo: Cultrix, 1990.

SCOTT, E. C. The creation/evolution continuum. California Journal of Science Education, Sacramento, v. 1, n. 2, p. 61-73, 2001.

SEPÚLVEDA, C.; EL-HANI, C. N. Quando visões de mundo se encontram: religião e ciência na trajetória de formação de alunos protestantes de uma licenciatura em ciências biológicas. Investigações em Ensino de Ciências, Porto Alegre, v. 9, n. 2, p. 137-175, 2004.

SILVA, D. V. C. Análise do desenvolvimento de conceitos científicos sobre a teoria da evolução das espécies em alunos do ensino médio. 2004. 166 f. Dissertação (Mestrado em Educação) - Centro de Educação e Ciências Humanas, Universidade Federal de São Carlos, São Carlos, 2004.

SMITH, M. U.; SIEGEL, H.; McINERNEY. Foundational issues in evolution education. Science \& Education, Chicago, v. 4, n. 1, p. 23-46, 1995.

SOARES, J. L. O rastro da vida: uma pequena história de bilhões de anos. São Paulo: Moderna, 1990.

STORNIOLO, I.; BALANCIN, E. M. O livro do gênesis: origem da vida e da história. 8. ed. São Paulo: Paulus, 2003.

TAMBOSI, O. A velha cruzada dos criacionistas contra Darwin e o evolucionismo. Lisboa: Crítica, 1999.

Artigo recebido em 01/08/2011. Aceito em 28/01/2012. 